\title{
CONTAINER TERMINAL SPATIAL PLANNING - A 2041 PARADIGM FOR THE WESTERN CAPE PROVINCE IN SOUTH AFRICA
}

\author{
JAN HAVENGA* \\ DAVID KING \\ ZANE SIMPSON \\ LEILA GOEDHALS-GERBER \\ ANNEKE DE BOD \\ *janh@sun.ac.za \\ Department of Logistics \\ Stellenbosch University, South Africa
}

\begin{abstract}
This paper investigates the suitable location for an intermodal inland container terminal (IICT) in the city of Cape Town. A container market segmentation approach is used to project growth for container volumes over a 30-year period for all origin and destination pairings on a geographical district level in an identified catchment area. The segmentation guides the decision on what type of facility is necessary to fulfil capacity requirements in the catchment area and will be used to determine the maximum space requirements for a future IICT. Alternative sites are ranked from most suitable to least suitable using multi-criteria analysis, and preferred locations are identified. Currently, South Africa's freight movement is dominated by the road sector. Heavy road congestion is thus prevalent at the Cape Town Container Terminal (СTCT). The paper proposes three possible alternative sites for an IICT that will focus on a hub-and-spoke system of transporting freight.
\end{abstract}

\section{INTRODUCTION}

Containerised international trade has grown exponentially over the past few years and is the fastest growing cargo segment since 1990 (UNCTAD, 2011). This is fuelled by an increasing proportion of commodities being containerised to promote ease of handling and movement of goods (Garratt, 2006; Rodrigue, 2007; US Department of Transportation, 2011). According to Davies (2007) these increased volumes are placing growing pressure on terminal capacity with ports challenged by the expansion of on-dock capacity due to constraints on land availability, environmental issues, and concerns from local communities regarding traffic congestion and impact on quality of life. He concludes that 'these factors have generated growing interest in the concept of inland container terminals as a means of boosting capacity, through potential reductions in container dwell time at on-dock terminals and the transfer of non-essential terminal activity to inland locations'. 
This state of affairs also holds true for the South African situation and for the Port of Cape Town, which has limited expansion capacity within the current Cape Town Container Terminal (СTCT). The port handled a total of 708526 twenty-foot equivalent units (TEUs) in 2010 with a 50/50 split between imports and exports (Transnet National Ports Authority, 2010). The port container expansion plan provides for 4.4 million TEUs in 2050 (a more than five-fold growth), but this will only be possible if infrastructure expands in a seaward direction. The pressure on port capacity will therefore become more pronounced in future and it is envisaged that an inland intermodal container terminal (IICT) could alleviate some of this pressure. For the purpose of this paper an IICT is seen as a consolidation and deconsolidation point for empty and loaded containers; it thus acts as an inland intermodal trans-shipment and distribution point, but could also offer services such as storage, trackand-trace and maintenance of containers.

\section{RESEARCH STRATEGY}

\section{Research approach}

The expected growth in container volumes in the Western Cape province in South Africa necessitates the expansion of container terminal capacity. Land restrictions at the port dictate the development of an IICT located in the City of Cape Town that can support the CTCT in meeting future demand capacity and functional handling requirements for containers. Suitable sites for the IICT need to be identified.

To select a suitable site the first step is to characterise the functional scope and size of an intermodal container terminal business in the Cape Town area that aligns with the future development of the container freight industry and captures a substantial market share. The site selection will be informed by forecast regional growth in freight, traffic and economic activity in the context of provincial and municipal spatial and transport planning.

\section{Methods of data gathering}

Container volumes for this study are obtained from the South African Freight Demand Model (FDM). It provides a comprehensive measure of freight flows for all modes between 372 geographical districts of South Africa on a 71 commodity level. The FDM also forecasts these flows 30 years into the future with five-year intervals. It utilises a disaggregated social accounting matrix framework based on magisterial district supply and demand. The results are compared with detailed industry research and correlated with known freight flows (GAIN, 2012). The container demand forecast is based on commodity-level export and import-volume forecasts, as well as the propensities of the commodities to be containerised. The methodology for container demand forecasting is therefore driven by information on container content, forecasts of long-term growth in demand for this content, and 'fitting' these to maximum propensities to containerise. This provides more accurate forecasts than purely extrapolating historical trends (Havenga \& Van Eeden, 2011). 


\section{Procedure}

The maximum size and possible location(s) for the IICT are identified through the development of appropriate container market segmentation, based on the movement characteristics of containers through and in a designated catchment area. This also indicates what type of facility should satisfy future demand for container movements on a spatial and functional level.

\section{DISCUSSION}

\section{Catchment area}

The catchment area for the IICT was based on the extent of the railway lines that service the Port of Cape Town and the surrounding geographical districts. The presumption was also made that any future terminal will operate on a hub-and-spoke system with all rail freight originating within or destined for the area passing through the terminal (refer to Figure 1).

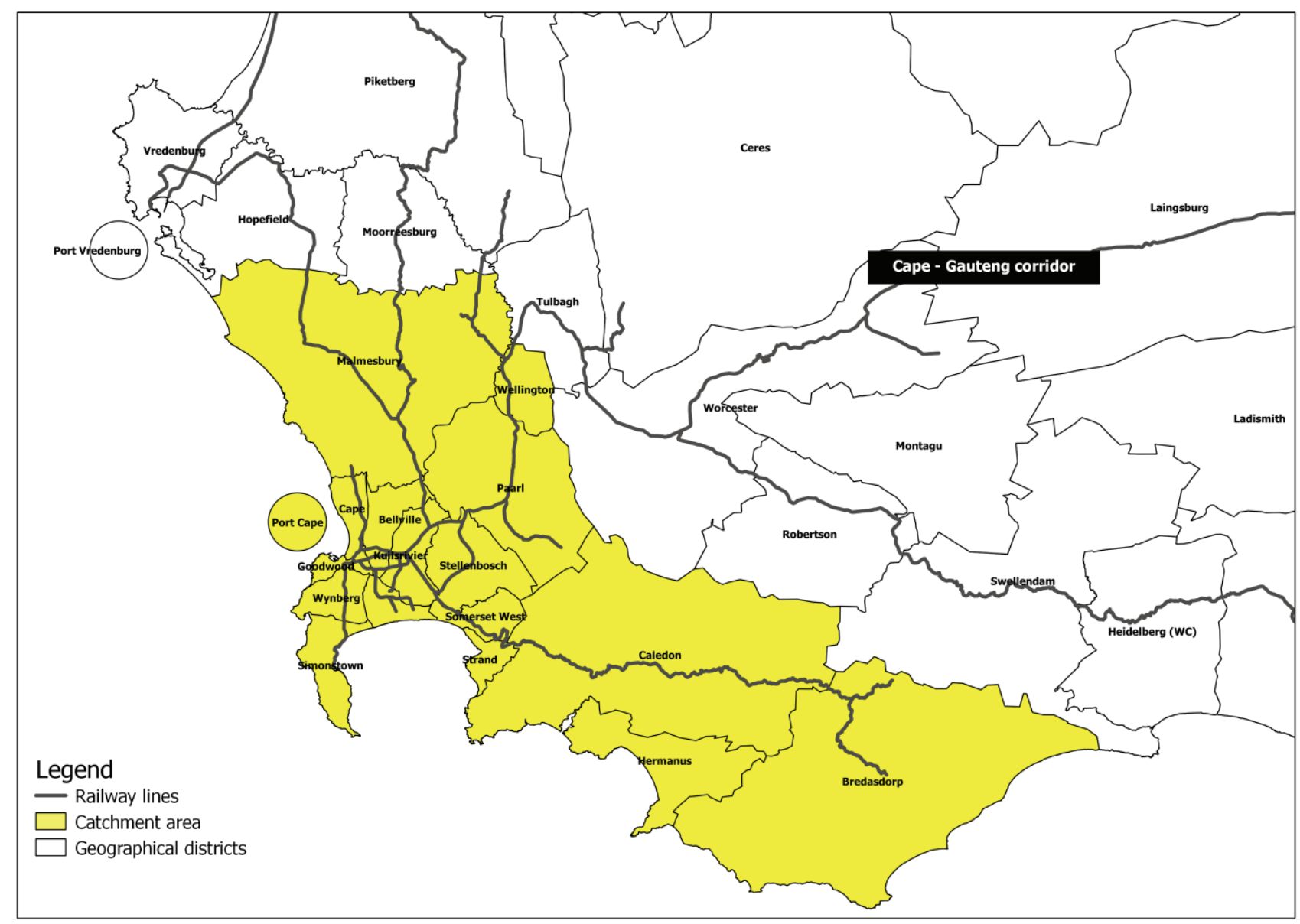

Figure 1: Catchment area for proposed IICT

Currently, almost all containers are transported by road to and from the CTCT. A future intermodal or bi-modal solution that incorporates rail is envisaged for the IICT. 


\section{Defining the segmented container freight flows}

A key point of departure is that any future IICT would most probably not handle all container volumes in a designated area and therefore it is necessary to do a proper market segmentation of container flows. Based on the container handling profile of the current container depot located in the Bellville geographical district, and the type of movements that are best suited to rail transport, it was decided that a future IICT in the Western Cape will accommodate six types of container freight flows. They are listed and briefly discussed in Table 1.

\section{Table 1: Segmented container freight flows}

\begin{tabular}{|c|l|l|}
\hline $\begin{array}{c}\text { Segment } \\
\text { number }\end{array}$ & \multicolumn{1}{|c|}{ Name } & \multicolumn{1}{c|}{ Description } \\
\hline 1 & $\begin{array}{l}\text { Imported long } \\
\text { distance }\end{array}$ & $\begin{array}{l}\text { Imported container-friendly commodities transferred by rail from the } \\
\text { CTCT travelling north on the Cape-Gauteng corridor }\end{array}$ \\
\hline 2 & $\begin{array}{l}\text { Exported long } \\
\text { distance }\end{array}$ & $\begin{array}{l}\text { Container-friendly commodities travelling south on the Cape-Gauteng } \\
\text { corridor and exported through the CTCT }\end{array}$ \\
\hline 3 & $\begin{array}{l}\text { Exported local } \\
\text { customers }\end{array}$ & $\begin{array}{l}\text { High volume local exporters that export deciduous fruit, processed } \\
\text { foods, beverages, citrus or motor vehicle parts and accessories (the top } \\
\text { five export commodities) through the port }\end{array}$ \\
\hline 4 & $\begin{array}{l}\text { Domestic } \\
\text { intermodal } \\
\text { north }\end{array}$ & $\begin{array}{l}\text { Container-friendly commodities from districts in the catchment area } \\
\text { travelling northbound on the Cape-Gauteng corridor }\end{array}$ \\
\hline 5 & $\begin{array}{l}\text { Domestic } \\
\text { intermodal } \\
\text { south }\end{array}$ & $\begin{array}{l}\text { Container-friendly commodities travelling southbound on the } \\
\text { Cape-Gauteng corridor destined for catchment area districts }\end{array}$ \\
\hline 6 & $\begin{array}{l}\text { Empty } \\
\text { containers }\end{array}$ & $\begin{array}{l}\text { Empties are estimated as a percentage of loaded containers: } \\
\text { Imported empties are 49\% of loaded export TEUs } \\
\text { - Exported empties are 43\% of loaded import TEUs } \\
\text { - Domestic intermodal empties are 36\% of loaded TEUs }\end{array}$ \\
\hline
\end{tabular}

The segmented flows are underpinned by a future road-rail intermodal solution for South Africa where a modal shift to rail is aggressively pursued and more rail-friendly commodities are containerised. Furthermore, the segmentation guides the decision on what type of facility is necessary to fulfil capacity requirements in the catchment area and will be used to determine the maximum space requirements for a future IICT.

\section{Space requirement for the IICT}

The maximum spatial requirements for the IICT are estimated by using a land utilisation measure of containers per hectare (ha) per year. This metric evaluates the efficiency of both operations (throughput) and land use. Analysis of a number of studies shows that an acceptable lower and upper bound for this metric would be 2000 to 13000 TEUs and an average would be 6000 TEUs per ha per year (Le-Griffin \& Murphy, 2006; Tioga Group, 2010). 


\section{Alternative site selection}

Stakeholder consultation took place in the policy and regulatory environment, the spatial development and transport environment for the City of Cape Town. An extensive literature study of relevant regulations and policy papers were supplemented with personal interviews with City of Cape Town representatives and Transnet employees. During stakeholder consultation, factors to take into account when identifying potential sites in the catchment area were identified. It was advocated that a suitable site should:

- be located near the centre of production for a catchment area with sufficient demand to ensure the viability of a terminal

- have good mainline access and a direct rail connection

- be directly connected to the major road highway network

- take consideration of environmental and socio-economic impacts on the surrounding area.

There should also be enough available and suitable land for construction and expansion.

Furthermore, a future IICT would essentially need to:

- promote inter- and bi-modality

- render a port service

- provide a solution to empty containers stacking in the port precinct

- alleviate road traffic congestion in the inner-city area

- be ultimately future proof.

The identified sites were assessed based on three primary criteria, namely, land utilisation (low-key, normal-key or high-key design); rail efficacy (existence of a direct line, railway within $500 \mathrm{~m}$ and overhead electrical lines); and road efficacy (proximity to a freeway, distance from port and access to main roads). The sites were chosen on a very high pre-feasibility level and therefore other factors such as environmental, social and financial suitability and sustainability do not form part of this assessment. This site selection process falls into a Front-end loading (FEL) 0 identification phase and has at its main purpose the narrowing down of site choices after which a more elaborate FEL 1, appraisal and selection phase can be conducted. Therefore the three primary criteria as chosen above gave a sound indication of which sites could be further investigated.

\section{Analysis and results}

The total loaded container volumes (as extracted out of the FDM) originating in and destined for the catchment area and the compounded annual growth rate (CAGR) for 2010 and for the forecast interval years are shown in Table 2, and graphically depicted in Figure 2. It is forecast that almost 2.2 million loaded TEUs will be handled in the catchment area in 2041. 
Table 2: Total loaded container volumes and CAGR for the catchment area

\begin{tabular}{|c|c|c|}
\hline Year & TEUs & CAGR \\
\hline 2010 & 651240 & - \\
\hline 2016 & 831132 & $4.15 \%$ \\
\hline 2021 & 1007794 & $4.05 \%$ \\
\hline 2026 & 1198529 & $3.89 \%$ \\
\hline 2041 & 2173114 & $3.96 \%$ \\
\hline
\end{tabular}

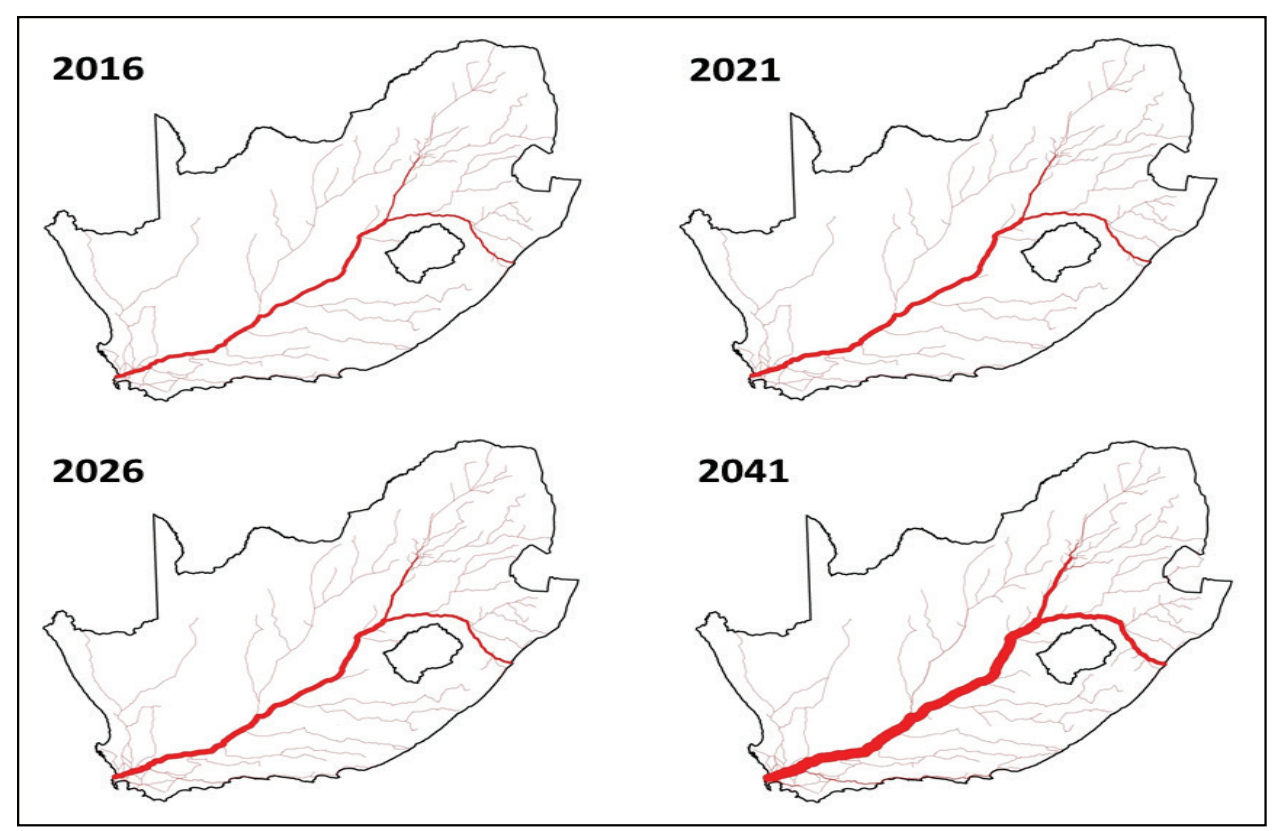

Figure 2: Forecast inland loaded container flows to and from the catchment area

The segmented container volumes (which could potentially be captured by an IICT) are shown in Table 3 for the base year (2010) and the forecast intervals up to 2041. The total container volume that could be handled by a future IICT in 2041 is calculated as 723121 TEUs of which $69 \%$ will be loaded containers and $31 \%$ empties.

Table 3: Summary of base year and forecast segmented container volumes (TEUs)

\begin{tabular}{|c|l|c|c|c|c|c|}
\hline Segment & Year & $\mathbf{2 0 1 0}$ & $\mathbf{2 0 1 6}$ & $\mathbf{2 0 2 1}$ & $\mathbf{2 0 2 6}$ & $\mathbf{2 0 4 1}$ \\
\hline 1 & Imported long-distance & 38244 & 52170 & $\mathbf{6 6} 118$ & 81235 & 153974 \\
\hline 2 & Exported long-distance & 33593 & 42972 & 50791 & 59038 & 97364 \\
\hline 3 & Exported local customers & 92558 & 107906 & 116901 & 124741 & 152862 \\
\hline 4 & Domestic intermodal northbound & 8396 & 11200 & 14442 & 18513 & 45399 \\
\hline 5 & Domestic intermodal southbound & 9137 & 12266 & 15867 & 20377 & 50264 \\
\hline \multirow{2}{*}{6} & Imported empties & 61814 & 73930 & 82169 & 90051 & 122611 \\
\cline { 2 - 7 } & Exported empties & 16445 & 22433 & 28431 & 34931 & 66209 \\
\cline { 2 - 7 } & Domestic empties & 6312 & 8448 & 10911 & 14000 & 34439 \\
\hline Total TEUs & & $\mathbf{2 6 6 4 9 9}$ & $\mathbf{3 3 1 3 2 5}$ & $\mathbf{3 8 5} \mathbf{6 3 1}$ & $\mathbf{4 4 2} \mathbf{8 8 6}$ & $\mathbf{7 2 3} \mathbf{1 2 1}$ \\
\hline
\end{tabular}


The forecast volumes indicate that a strong focus is required on long-distance import and export container movements while accommodating large volumes from local exporters and expanding the domestic intermodal market. This change in focus is in line with the South African government's policy to shift more freight from road to rail and also with the goals of Transnet Freight Rail (TFR) to target rail-friendly commodities and of moving more palletised commodities into containers.

The results are used to quantify the maximum space requirements for the future IICT.

\section{Space requirement for the IICT}

Table 4 shows the maximum future spatial requirements (in hectares [ha]) for each forecast year based on the limits defined in the research approach.

Table 4: Maximum future spatial requirements for the IICT

\begin{tabular}{|c|c|c|c|c|}
\hline Land utilisation & TEUs/ha/year & Year & TEUs & ha \\
\hline Lower limit & 2000 & \multirow{3}{*}{2010} & \multirow{3}{*}{266499} & 133 \\
\hline Middle & 6000 & & & 44 \\
\hline Upper limit & 13000 & & & 20 \\
\hline Lower limit & 2000 & \multirow{3}{*}{2016} & \multirow{3}{*}{331325} & 166 \\
\hline Middle & 6000 & & & 55 \\
\hline Upper limit & 13000 & & & 25 \\
\hline Lower limit & 2000 & \multirow{3}{*}{2021} & \multirow{3}{*}{385631} & 193 \\
\hline Middle & 6000 & & & 64 \\
\hline Upper limit & 13000 & & & 30 \\
\hline Lower limit & 2000 & \multirow{3}{*}{2026} & \multirow{3}{*}{442886} & 221 \\
\hline Middle & 6000 & & & 74 \\
\hline Upper limit & 13000 & & & 34 \\
\hline Lower limit & 2000 & \multirow{3}{*}{2041} & \multirow{3}{*}{723121} & 362 \\
\hline Middle & 6000 & & & 121 \\
\hline Upper limit & 13000 & & & 56 \\
\hline
\end{tabular}

Depending on the level of capacity utilisation (low, medium or high) the maximum space requirement by 2041 for the IICT would be 362 ha, 121 ha and 56 ha, respectively.

\section{Alternative site selection}

Eleven potential sites in the catchment area were identified through stakeholder consultation using the criteria defined in the research approach. Four sites are located within the City of Cape Town urban area (the Atlantis, Kraaifontein [two options] and Kuilsrivier areas); another four are owned by the government or private entities (Acacia Park and Firgrove properties, Wingfield Naval Base and Ysterplaat Air Force base); and three more are owned by Transnet (Salt River property and Bellville and Culemborg precincts). 
Table 5 shows the assessment of the 11 locations against the primary criteria.

Table 5: Location feasibility, road and rail efficacy of selected sites for 2016 and 2041

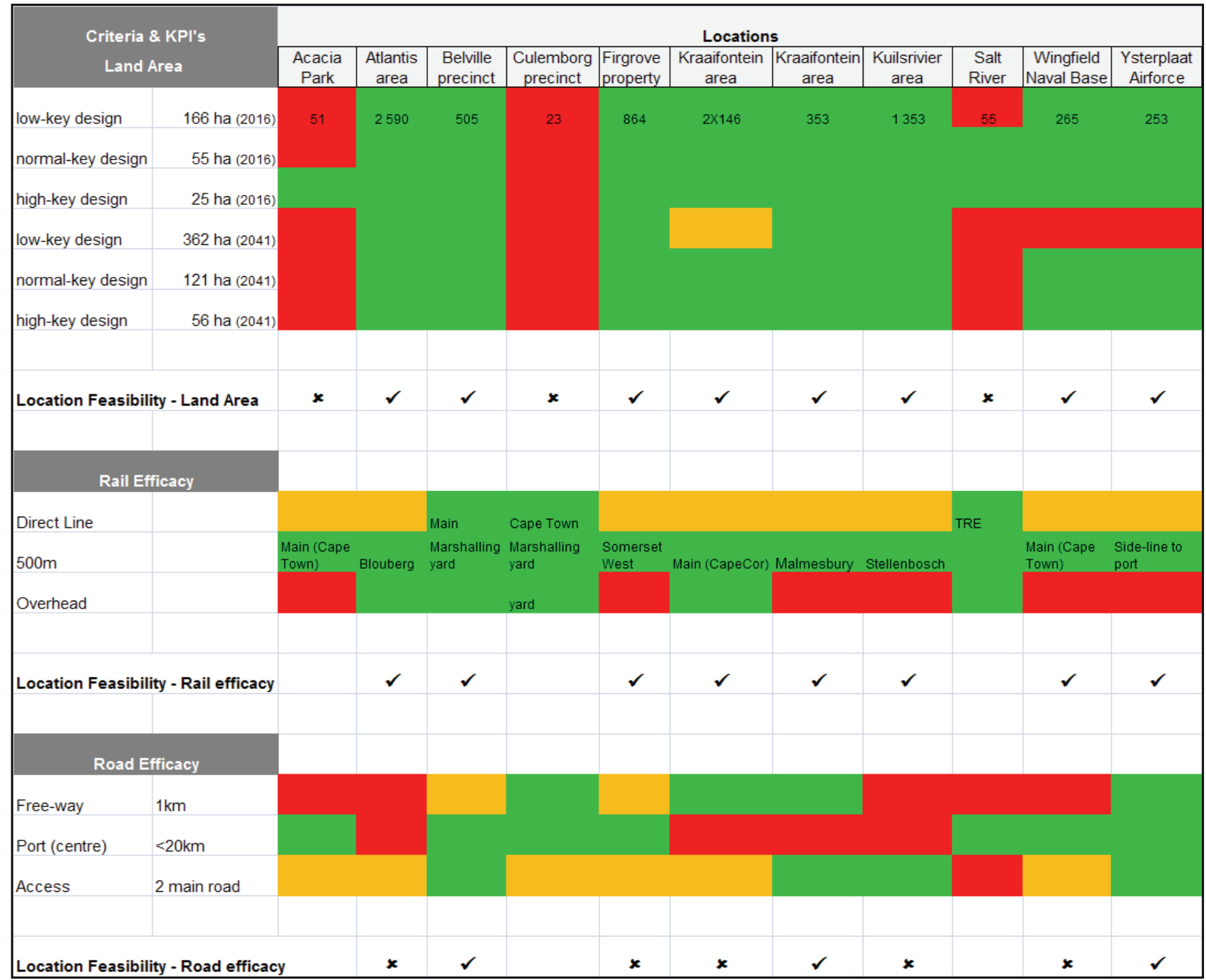

Three potential sites are accordingly identified as a suitable location for a future IICT. They are the Bellville precinct, Kraaifontein area (second option) and the Ysterplaat Air Force base. Figure 3 shows the capacity utilisation of the three chosen locations over time.

All three sites will have sufficient space if the future terminal is operated at a medium-tohigh capacity utilisation level. Ysterplaat and Kraaifontein will run out of space by 2030 and 2040, respectively, on a low capacity utilisation level.

\section{Location of potential sites}

Figure 4 gives a birds-eye view of the three potential sites in relation to the Port of Cape Town and the CTCT. 


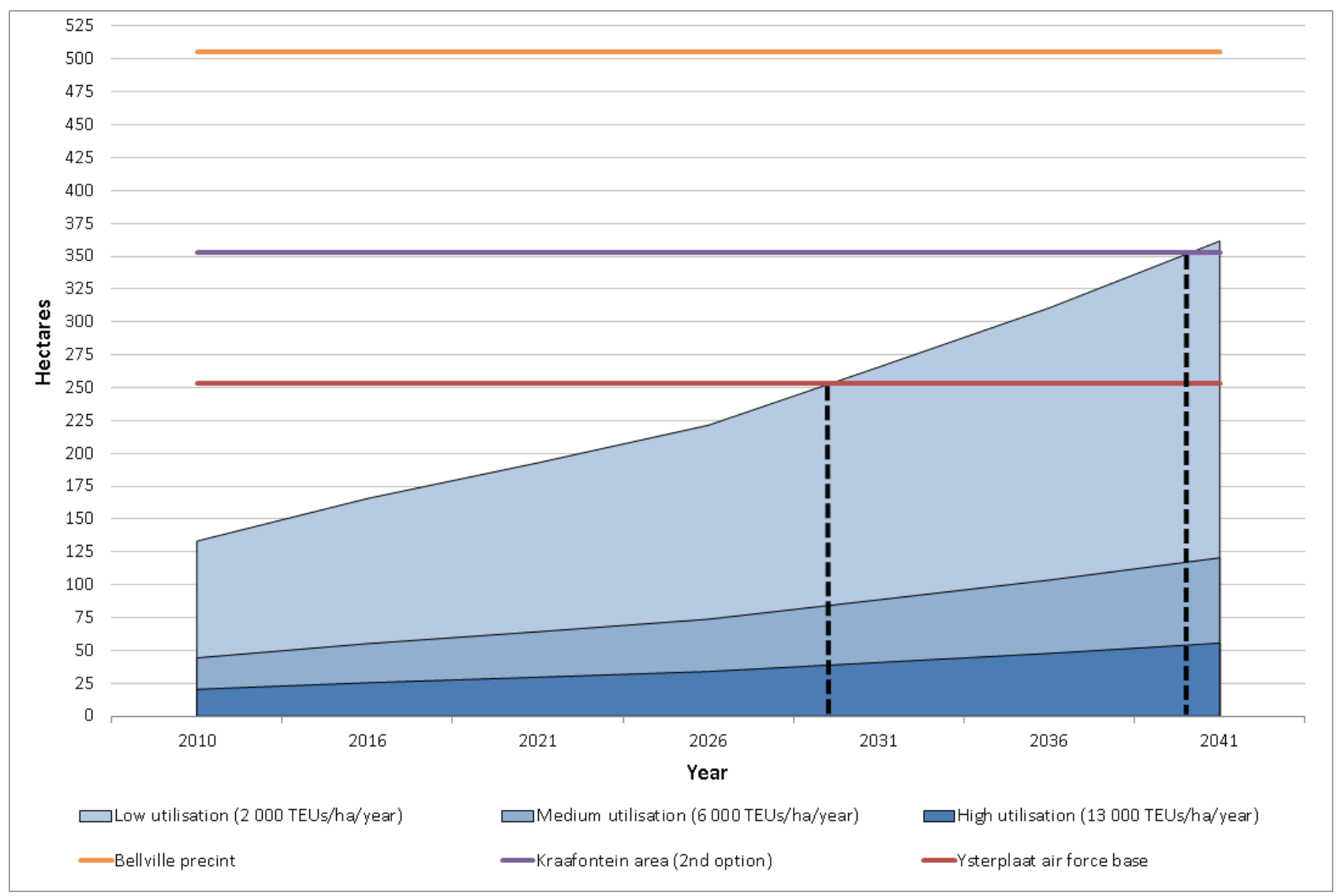

Figure 3: Capacity utilisation of potential locations over time

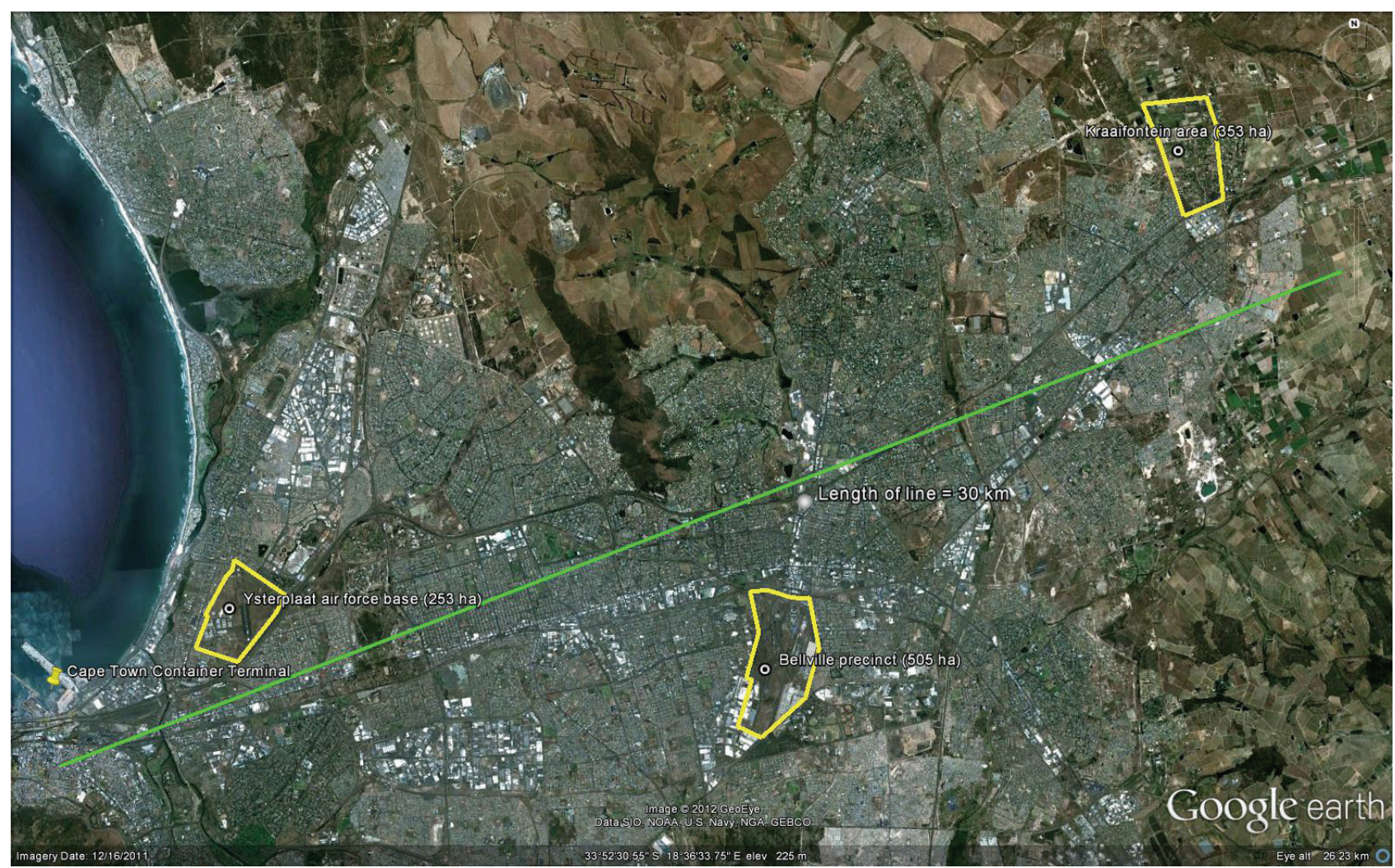

Figure 4: Location of the three potential sites in relation to the Port of Cape Town 
Ysterplaat falls within a $5 \mathrm{~km}$ radius, Bellville and Kraaifontein within a $15 \mathrm{~km}$ and $30 \mathrm{~km}$ radius, respectively. All three these sites have major road and rail access within $500 \mathrm{~m}$. Ysterplaat Air Force base is located between the M5 and the N1 and there are off-ramps located at both ends of the site. Rail access can be established from the Cape Town Port feeder line that runs past Lagoon Beach and joins the main line near Acacia Park towards the Bellville railway precinct. The Kraaifontein site consists of a number of privately owned smallholdings with some industrial activity and is located just to the north of the N1, with the Malmesbury railway line running on the western border of the site. The Bellville precinct is owned by Transnet and has established rail access and is located within the N1, N2 and R300 road triangle.

\section{CONCLUSION}

Three potential sites were identified for the location of an IICT based on three primary criteria (land utilisation and road and rail efficacy). Space requirements for the IICT were calculated based on container flow segmentations for the catchment area. The availability of forecasts up to 2041 from South Africa's FDM indicate that these sites are future-proof (able to handle future container volumes) - therefore facilitating confidence in the required long-term investment decision.

The three sites were chosen on a high pre-feasibility level and the next step will be to conduct a proper location pre-feasibility study, including the following design and operational considerations:

- A trade-off between the cost of land and the cost of design when choosing which site is most suitable will need to be considered. Transnet (the state-owned rail and port infrastructure owner and operator) owns the Bellville precinct land and could afford a more low-key capacity utilisation design as this is also the biggest land area available. The other two sites will bring the complexity of buying land into the equation and will most probably require a medium-to-high capacity utilisation design. The restriction in size of any container terminal can be mitigated through the design, level of technology and automation employed on site.

- Adding functionality on site will increase the space requirements. Allowing warehousing and distribution functions or including back-of-port activities (such as storage or cold storage, offices, workshops, recreational facilities, commodity processing and restaurants) will add to the footprint of the container terminal.

- Providing dry-port functionality with customs clearance services and administration could alleviate congestion in the port precinct but will place added pressure on an IICT.

- Lastly, environmental, social and financial suitability and sustainability will also need to be analysed. 


\section{REFERENCES}

Davies, P. 2007. Challenges in Developing Viable Inland Container Terminals. Conference proceedings of the 2nd Annual National Urban Freight Conference held in Long Beach, CA.

GAIN (Growth and Intelligence Network). 2012. Freight Demand Model 2010, Stellenbosch, South Africa.

Garratt, M. 2006. Forecasting for long-term investment in the container shipping industrya holistic approach. MDS Transmodal. Available from: http://www.mdst.co.uk/attachments/ downloads/Hamburg_Dec06.pdf (Accessed 18 July 2011).

Havenga, J.H. \& Van Eeden, J. 2011. Forecasting South African containers for international trade: A commodity-based approach. Journal of Transport and Supply Chain Management 5(1): 170-85.

Le-Griffin, H.D. \& Murphy, M. 2006. Container terminal productivity. USA: University of Southern California.

Rodrigue, J-P. 2007. Gateways, corridors and global freight distribution: The Pacific and North American maritime/land interface. Conference proceedings of the International Conference on Gateways and Corridors held in Pan Pacific Vancouver: Vancouver, 2-4 May 2007.

Tioga Group. 2010. Improving marine container terminal productivity, Prepared for the Cargo Handling Cooperative Program, USA.

Transnet National Ports Authority. 2010. Port Statistics 2010. Unpublished figures, South Africa.

United Nations Conference on Trade and Development (UNCTAD). 2011. Review of Maritime Transport 2011, United Nations Publications, New York, USA.

US Department of Transportation. 2011. America's Container Ports: Linking Markets at Home and Abroad. Washington DC: Bureau of Transportation Statistics, US Department of Transportation. 


\section{Table of acronyms}

\begin{tabular}{|l|l|}
\hline CAGR & Compounded Annual Growth Rate \\
\hline CTCT & Cape Town Container Terminal \\
\hline FDM & Freight Demand Model \\
\hline FEL & Front-End Loading \\
\hline IICT & Intermodal Inland Container Terminal \\
\hline TEU & Twenty-foot Equivalent Unit \\
\hline TFR & Transnet Freight Rail \\
\hline UNCTAD & United Nations Conference on Trade and Development \\
\hline
\end{tabular}

